\title{
Host Identity Protocol (HIP) as a Virtual Learning Object
}

\author{
Laura Bergström, Johan Fröjdman, Kaj J. Grahn, \\ Jonny Karlsson, and Göran Pulkkis \\ Arcada University of Applied Sciences, Helsinki, Finland \\ laura.bergstrom@arcada.fi, johan.frojdman@arcada.fi, \\ jonny.karlsson@arcada.fi, kaj.grahn@arcada.fi, \\ goran.pulkkis@arcada.fi
}

\begin{abstract}
This paper presents a virtual learning environment for HIP (Host Identity Protocol). HIP is a potential future Internet protocol currently under research. The main idea with HIP is the separation between the location and identity information by introducing a new cryptographic name space, called Host Identity (HI). This feature provides enhanced network security as well as easy management of mobility and multi-homing. Overviews of the basic features and implementations of HIP are included in the paper. A technical description of HIP, including a survey of specifications and details about the functionality of the protocol, is included in an appendix. The HIP learning environment has been produced to serve both contact and distance education in advanced networking. The development of the learning environment is described. A list of topics that developers of a learning environment should think of when designing the user interface is presented based on a theory on the structure of human behaviour. This theory is included in an appendix. The chosen didactical approach, the structured animation of HIP features, and the graphical design of the learning platform are presented and motivated. The IT tools and infrastructure needed to implement and use the learning platform are also described.
\end{abstract}

Keywords: animation, didactical, learning environment, HIP, security, mobility 